\title{
Reduction of microbleeds by immunosuppression in a patient with $A \beta$-related vascular inflammation
}

\section{OPEN}

Andreas Traschütz, MD

Theophilos Tzaridis, MD

Arndt-Hendrik Penner, MD

Klaus Kuchelmeister, MD

Horst Urbach, MD

Elke Hattingen, MD

Michael T. Heneka, MD

Correspondence to

Dr. Heneka:

michael.heneka@

ukb.uni-bonn.de

\section{ABSTRACT}

Objective: To investigate whether the occurrence or clearance of microhemorrhages in cerebral amyloid angiopathy (CAA)-related vascular inflammation can be modified by immunosuppressive treatment.

Methods: Clinical and radiologic follow-up for more than 5 years of a patient with histopathologically confirmed CAA-related vascular inflammation treated with a prolonged and tapered regimen of IV cyclophosphamide and oral steroids.

Results: Under long-term immunosuppressive treatment, a reduced number of cortical micobleeds was observed on repeat MRls because of both the prevention of new microbleeds and the clearance of those existing at baseline.

Conclusions: Sustained immunosuppression should be considered and systematically investigated as a treatment option for cortical microbleeds in CAA and related inflammatory phenotypes.

Classification of evidence: This study provides Class IV evidence. This is a single observational study without controls. Neurol Neuroimmunol Neuroinflamm 2015;2:e165; doi: 10.1212/ NXI.0000000000000165

\section{GLOSSARY}

$\mathbf{A} \boldsymbol{\beta}=\boldsymbol{\beta}$-amyloid; $\mathbf{A B R A}=\mathrm{A} \beta$-related angiitis $; \mathbf{A D}=$ Alzheimer dementia; $\mathbf{C A A}=$ cerebral amyloid angiopathy; $\mathbf{C A A}-\mathbf{r} \mathbf{i}=\mathbf{C A A}$ related inflammation; FLAIR $=$ fluid-attenuated inversion recovery.

Cerebral amyloid angiopathy-related inflammation (CAA-ri) and $\beta$-amyloid (A $\beta$ )-related angiitis (ABRA) represent a subgroup of cerebral amyloid angiopathy (CAA). Whereas CAA predominantly presents with recurrent lobar intracranial hemorrhages, CAA-ri and ABRA are clinically characterized by subacute focal neurologic deficits and encephalopathy with progressive cognitive impairment, behavioral alterations, psychosis, focal or generalized seizures, and headache. Histologic features of CAA-ri consist of segmental perivascular inflammatory infiltrates and ABRA shows vasculitic, transmural, often granulomatous inflammatory infiltrates that are similar to those seen in primary angiitis of the CNS. Accordingly, current treatment regimens consist mainly of aggressive immunosuppressive therapy with steroids and cytostatic agents such as cyclophosphamide and azathioprine. However, treatment strategies and reported outcomes for ABRA and CAA-ri vary substantially, and both prospective studies and reports on clinical experiences are desperately needed to improve the current therapeutic strategies for this disease. In this study, we present a patient with pathologic features of ABRA and CAA-ri in whom a prolonged and tapered immunosuppressive treatment with steroids and cyclophosphamide not only resolved encephalopathy and clinical symptoms but also was associated with a reduced number of microbleeds as radiologic features of CAA.

\footnotetext{
From the Departments of Neurology (A.T., T.T., M.T.H.), Neuroradiology (A.-H.P., E.H.), and Neuropathology (K.K.), University of Bonn, Germany; Department of Neuroradiology (H.U.), University of Freiburg, Germany; and German Center for Neurodegenerative Disease (M.T.H.), Bonn, Germany.

Funding information and disclosures are provided at the end of the article. Go to Neurology.org/nn for full disclosure forms. The Article Processing Charge was paid by Michael T. Heneka.

This is an open access article distributed under the terms of the Creative Commons Attribution-NonCommercial-NoDerivatives License 4.0 (CC BY-NC-ND), which permits downloading and sharing the work provided it is properly cited. The work cannot be changed in any way or used commercially.
} 
CLINICAL CASE In December 2008, a 52-year-old right-handed Caucasian man was referred to our emergency department after a complex partial seizure. On admission, the patient was not oriented postictally and complained about hypesthesia of the right thigh and the fingertips as well as intermittent tinnitus; the remainder of the neurologic examination was normal. Otherwise healthy, the patient had experienced an acute otitis media 4 weeks prior to admission that was treated with antibiotics for 3 days. The patient's history included cigarette smoking, hypothyroidism, hypertension, and dyslipidemia. His regular medication included L-thyroxin, aspirin, metoprolol, ramipril, and simvastatin at usual dosages. His father had been diagnosed with Alzheimer dementia (AD), but the family history was unremarkable for further $\mathrm{AD}$ cases or other neurologic diseases.

Consistent with left temporal intermittent epileptiform activity in the first EEG, the initial CT scan revealed a subcortical hypodensity with contrast enhancement in the left parieto-occipital-temporal lobe. A cranial MRI showed diffuse cerebral edema in the right frontobasal and temporal region, as well as in the left temporopolar compartment with multiple parenchymal hemorrhages (figure 1). Diffusionweighted and contrast-enhanced images, including a venous angiogram, were normal. Cerebral venous sinus thrombosis and dural arteriovenous fistulae were excluded by catheter angiography. An otolaryngeal examination was unremarkable, and a CT scan revealed fluid retention in the left mastoid without affecting the bone. Blood tests including a screening for thrombophilia were normal except for low thyroid-stimulating hormone and a mild elevation of C-reactive protein. CSF analysis including ferritin showed an elevated protein of $559 \mathrm{mg} / \mathrm{L}$ (range $<500$ ) but was otherwise normal. Antiepileptic treatment was initiated with carbamazepine and the patient was discharged.

Upon progression of the fluid-attenuated inversion recovery (FLAIR) hyperintensities in a followup MRI 6 weeks later (figure 1), 2 brain biopsies were taken from the lesion in the right frontal lobe. Both specimens showed Congo red-positive thickening of cortical and leptomeningeal vessel walls accompanied by multiple acute microhemorrhages and focal hemosiderin deposits. Immunohistochemical stainings revealed multiple, mostly diffuse, $A \beta$ deposits in the parenchyma but no evidence of tau pathology. The vessels with intramural $A \beta$ deposits often showed perivascular or transmural inflammatory infiltrates, including $\mathrm{CD}^{+}, \mathrm{CD}^{+}$, and some CD20 lymphocytes as well as $\mathrm{CD}^{+} 8^{+}$monocytes, multinucleated giant cells, and surrounding reactive astrocytes (figure 2 ). In some of these vessels, angiodestructive changes of their walls were seen. Based on these findings, a diagnosis of "cerebral $A \beta$ angiitis" was made and immunosuppressive treatment was initiated with daily oral prednisone and pulses of IV cyclophosphamide (table).

After 2 treatments with cyclophosphamide 4 weeks apart, there was marked clinical improvement and the patient reported a regression of his tinnitus
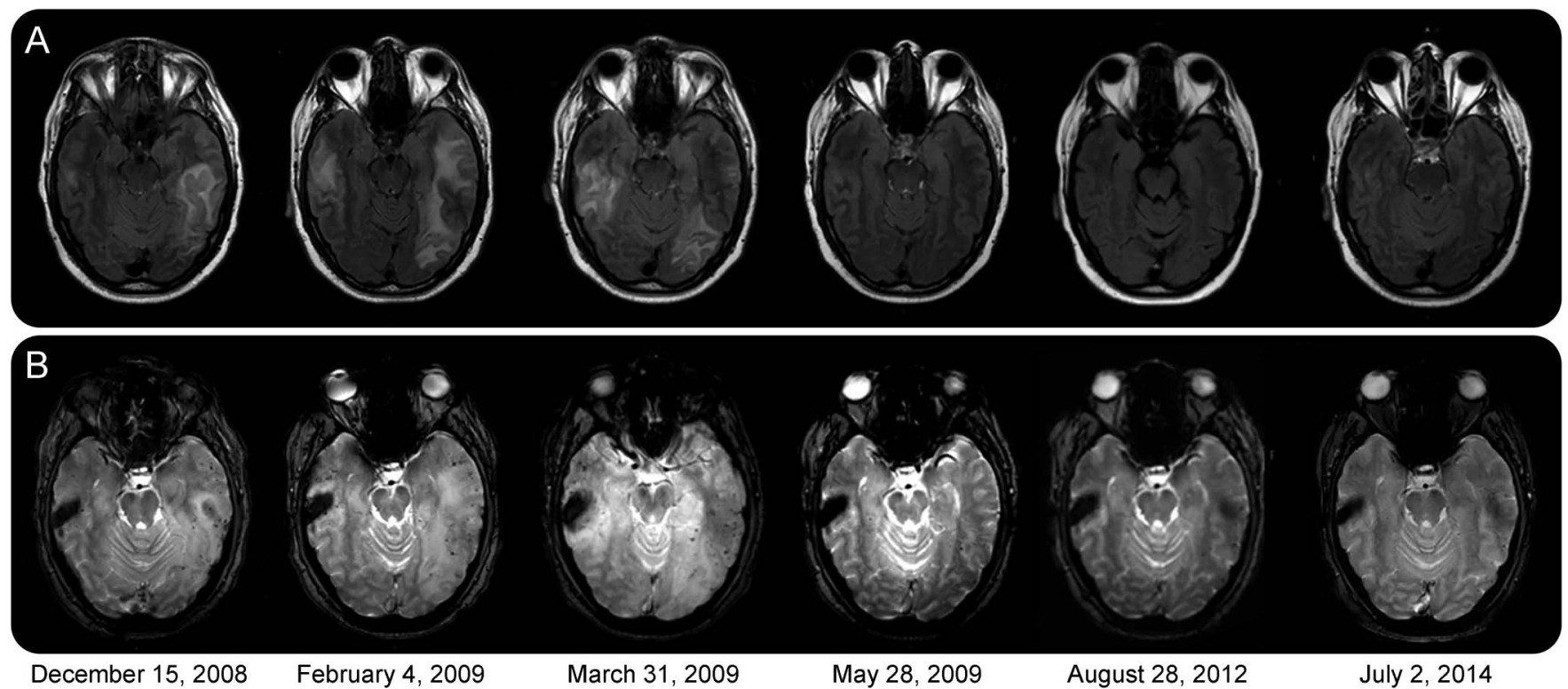

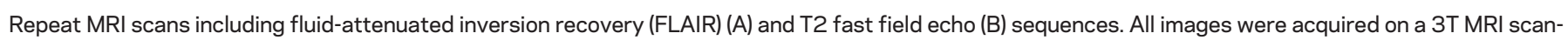

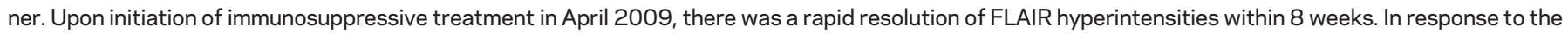
following maintenance therapy, the number of microbleeds markedly dropped. 


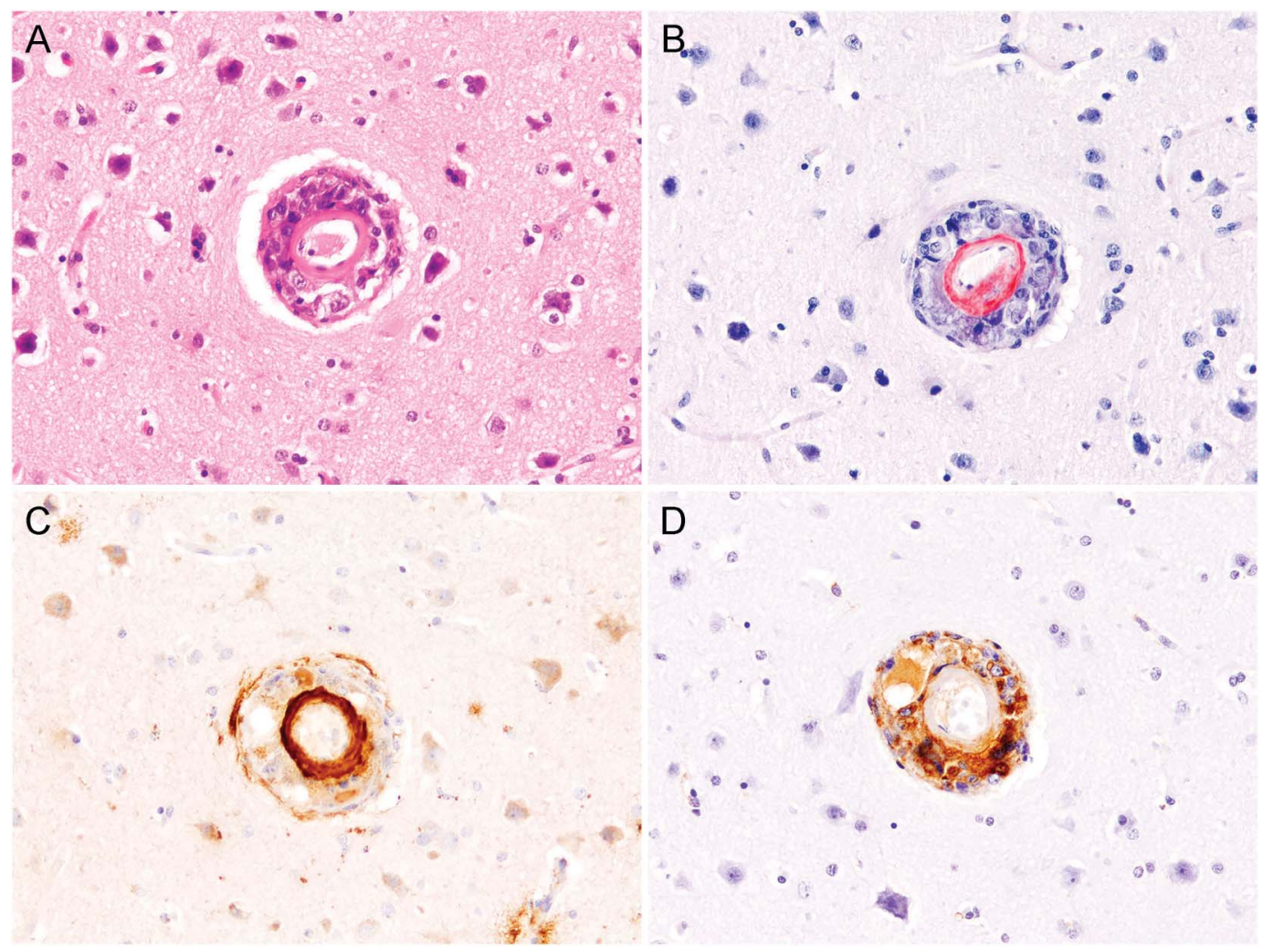

Hematoxylin \& eosin staining (A) revealed focal intramural inflammation including lymphocytes, multinuclear giant cells, and surrounding reactive astrocytes. Vascular amyloid deposits in cortical and leptomeningeal vessels were seen on Congo red stain (B) and immunohistochemical stainings against $\beta$-amyloid (C). Staining against CD68 (D) highlights monocytic involvement. All images taken at $200 \times$.

and partial improvement of the abovementioned hypesthesia. Delayed recall, which was shown to be mildly impaired in formal neuropsychological testing at baseline, was also restored. A follow-up MRI

\begin{tabular}{|lll|}
\hline Table Treatment regimen & \\
\hline Date & $\begin{array}{l}\text { Cyclophosphamide, } \\
\mathrm{mg} / \mathrm{m}^{2}\end{array}$ & $\begin{array}{l}\text { Prednisone, } \\
\mathrm{mg} / \mathrm{d}\end{array}$ \\
\hline April 3, 2009 & 750 & 100 \\
April 29, 2009 & 750 & 80 \\
May 27, 2009 & 750 & 80 \\
August 19, 2009 & 750 & 50 \\
March 3, 2010 & 750 & 20 \\
\hline September 22, 2010 & 750 & 10 \\
May 19, 2011 & 750 & 10 \\
May 16, 2012 & 375 & 10 \\
June 22, 2013 & 200 & 10 \\
August 22, 2013 & - & 5 \\
\hline
\end{tabular}

Pulses of IV cyclophosphamide were administered together with mesna and odansetron. The cumulative dose of $13.9 \mathrm{~g}$ remained below the estimated lower limit of $20 \mathrm{~g}$ for longterm myelotoxic side effects. Daily oral steroid treatment was supplemented with calcium and vitamin D. demonstrated near-complete resolution of T2/FLAIR hyperintensities (figure 1). Immunosuppressive treatment was continued, but oral prednisone was gradually tapered to a maintenance dose of $5 \mathrm{mg}$ and the time intervals between cyclophosphamide pulses gradually increased to $3,6,9$, and finally 12 months. In order to reduce the possible risk of secondary malignancies, ${ }^{1}$ pulse doses of cyclophosphamide were reduced to $375 \mathrm{mg} / \mathrm{m}^{2}$ in 2012 and to $200 \mathrm{mg} / \mathrm{m}^{2}$ in 2013 (table). During this treatment, the disease remained clinically and radiologically stable. Of note, there were no further microbleeds on repeat MRIs until July 2014, and the number of existing microbleeds was substantially reduced (figure 3).

Overall, immunosuppressive treatment was both effective and well tolerated. Cyclophosphamide was administered together with mesna and odansetron after exclusion of infections as well as regular full blood counts and control of renal and liver function. Because of an elevation of liver enzymes in response to carbamazapine, anticonvulsive treatment had already been switched to levetiracetam prior to immunosuppressive treatment, and the patient remained seizure-free. Steroid treatment was accompanied by supplementation with vitamin D and calcium, and 
Figure $3 \quad$ Comparison of microbleeds before and after treatment

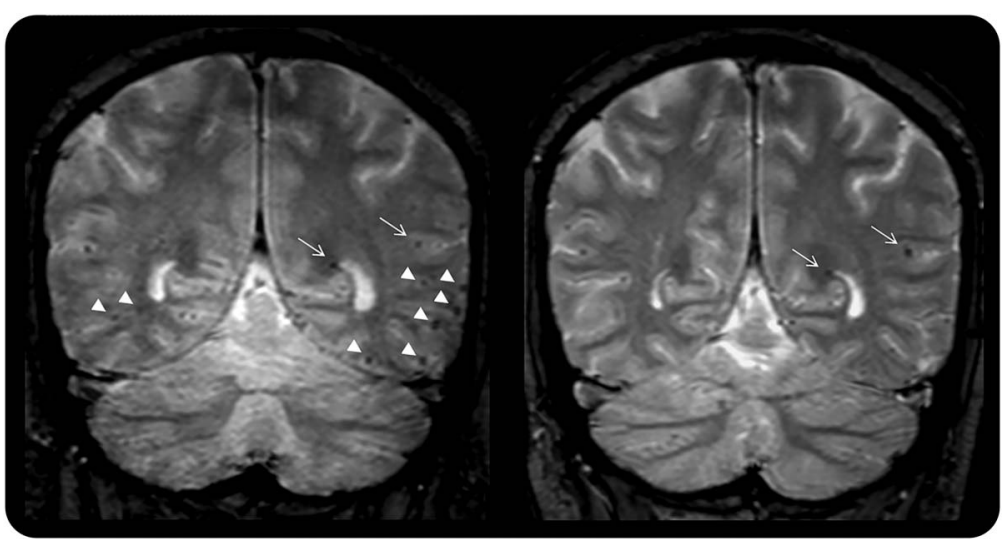

Coronal T2*-weighted image from May 2009 (left) shows multiple dotlike hypointense microbleeds mainly in the left temporal lobe. Although some lesions were still seen in 2014 (right, arrows), most of the microbleeds disappeared (arrowheads).

initial weight gain was well controlled by dietary measures. During treatment, the patient developed polyneuropathy, which improved upon replacement of vitamin B12 depletion. In 2011, the patient again noted difficulties with attention, memory, and word finding. Formal neuropsychological testing was unremarkable except for mild deficits in delayed recall. CSF examination showed a pathologic $\mathrm{A} \beta 42 / 40$ ratio of 0.05 (normal >0.09); absolute CSF levels of $\mathrm{A} \beta 42$, tau protein, and phosphorylated tau protein were within normal limits.

DISCUSSION Although A $\beta$-related CAA can present with variable symptoms, the clinical picture of the patient is highly consistent with the phenotypes described as $\mathrm{ABRA}^{2}$ and CAA-ri. ${ }^{3}$ Specifically, his presentation with mild cognitive impairment, seizure, and a focal neurologic deficit as well as his young age is in accordance with both ABRA and CAA-ri compared to CAA without inflammation. ${ }^{4}$ Of note, the patient had histopathologic features of both ABRA and CAA-ri, corroborating the suggestion that they are in fact part of a spectrum. ${ }^{4}$ In line with previous reports, there was marked improvement of T2/FLAIR-hyperintense lesions on MRI following treatment with oral steroids and/or cyclophosphamide. ${ }^{5}$ Only a very small number of patients have been reported to survive more than 60 months across the available literature.

As a novel finding, this patient also showed a reduction of CAA-associated microbleeds in response to immunosuppressive treatment.

This finding suggests that immune mechanisms contribute to the leakage of cerebral vasculature in CAA-ri and ABRA, since no further cortical microbleeds occurred under prolonged immunosuppressive therapy. Of note, disease activity in CAA-ri has recently been shown to be correlated with levels of
$\mathrm{A} \beta$ autoantibodies in the CSF. ${ }^{6}$ If such antibodies are indeed causative, immunosuppressive treatment may have prevented disease progression by suppressing their production by B cells.7 Alternatively, the treatment with steroids and/or cyclophosphamide ameliorated the toxicity of vascular $A \beta$ deposits by an inflammation-independent mechanism, for example by reducing the production of $A \beta$ or facilitating its phagocytic clearance. In fact, the gradual reduction of micobleeds under immunosuppression suggests that immune factors may suppress the local removal of preexisting microbleeds. Consistent with this, proinflammatory mediators such as cytokines have been found to impair microglial $A \beta$ clearance capacity in rodent models of cerebral amyloidosis. ${ }^{8,9}$ Therefore, immunosuppressive treatment could also decrease $A \beta$ levels as drivers of CAA-ri. Beyond that, we cannot exclude the possibility that microbleeds disappeared by regular clearance in the natural disease course. Following a short course of immunosuppressive treatment, however, a follow-up study including MRI with gradient echo and susceptibility-weighted sequences reported no more than the resolution of edema over a mean follow-up of 45 months in 12 patients with CAA-ri. ${ }^{5}$

Finally, the beneficial effect of sustained immunosuppressive therapy as observed in this single patient needs to be verified and if possible studied in a randomized trial. The pathologic demonstration of perivascular lymphomonocytic infiltrations in pure CAA, in both sporadic ${ }^{10,11}$ and familial ${ }^{11}$ forms, may suggest a similar angiodestructive role of inflammation. Because both lymphocytes and monocytes are targeted by cyclophosphamide, ${ }^{12,13}$ not only patients with ABRA and CAA-ri but all patients with CAA may benefit from an immunosuppressive therapeutic approach. Overall, this finding adds to the growing evidence for an interaction of inflammatory and degenerative mechanisms in neurodegenerative disorders. ${ }^{14}$

\section{AUTHOR CONTRIBUTIONS}

Dr. Andreas Traschütz: collection of clinical information, writing of manuscript, and critical revision of manuscript for important intellectual content. Theophilos Tzaridis: treatment of patient and critical revision. Dr. Arndt-Hendrik Penner, Prof. Horst Urbach, Prof. Elke Hattingen: MRI scans at different stages, figures, and critical revision for important intellectual content. Prof. Klaus Kuchelmeister: performing histopathologic examination, creation of figures, and critical revision for important intellectual content. Prof. Michael T. Heneka: design and concept of the study, patient treatment, writing of manuscript, and critical revision of manuscript for important intellectual content.

\section{STUDY FUNDING}

No targeted funding reported.

\section{DISCLOSURE}

A. Traschütz, T. Tzaridis, A.-H. Penner, K. Kuchelmeister, H. Urbach, and E. Hattingen report no disclosures. M.T. Heneka is on the editorial 
board for Journal of Neurochemistry, Journal of Chemical Neuroanatomy, and Molecular Neurobiology, is an associate editor for Neurology: Neuroimmunology \& Neuroinflammation, and received research support from DFG KFO177. Go to Neurology.org/nn for full disclosure forms.

Received May 20, 2015. Accepted in final form August 25, 2015.

\section{REFERENCES}

1. Curtis RE, Boice JD Jr, Stovall M, et al. Risk of leukemia after chemotherapy and radiation treatment for breast cancer. N Engl J Med 1992;326:1745-1751.

2. Scolding NJ, Joseph F, Kirby PA, et al. Abeta-related angiitis: primary angiitis of the central nervous system associated with cerebral amyloid angiopathy. Brain 2005;128:500-515.

3. Eng JA, Frosch MP, Choi K, Rebeck GW, Greenberg SM. Clinical manifestations of cerebral amyloid angiopathyrelated inflammation. Ann Neurol 2004;55:250-256.

4. Salvarani C, Hunder GG, Morris JM, Brown RD Jr, Christianson T, Giannini C. A $\beta$-related angiitis: comparison with CAA without inflammation and primary CNS vasculitis. Neurology 2013;81:1596-1603.

5. Kinnecom C, Lev MH, Wendell L, et al. Course of cerebral amyloid angiopathy-related inflammation. Neurology 2007;68:1411-1416.

6. Piazza F, Greenberg SM, Savoiardo M, et al. Anti-amyloid $\beta$ autoantibodies in cerebral amyloid angiopathy-related inflammation: implications for amyloid-modifying therapies. Ann Neurol 2013;73:449-458.
7. Cupps TR, Edgar LC, Fauci AS. Suppression of human B lymphocyte function by cyclophosphamide. J Immunol 1982;128:2453-2457.

8. Lee CY, Landreth GE. The role of microglia in amyloid clearance from the AD brain. J Neural Transm 2010;117: 949-960.

9. Heneka MT, Kummer MP, Stutz A, et al. NLRP3 is activated in Alzheimer's disease and contributes to pathology in APP/PS1 mice. Nature 2013;493:674-678.

10. Yamada $M$, Itoh $Y$, Shintaku $M$, et al. Immune reactions associated with cerebral amyloid angiopathy. Stroke 1996; 27:1155-1162.

11. Maat-Schieman ML, van Duinen SG, Rozemuller AJ, Haan J, Roos RA. Association of vascular amyloid beta and cells of the mononuclear phagocyte system in hereditary cerebral hemorrhage with amyloidosis (Dutch) and Alzheimer disease. J Neuropathol Exp Neurol 1997;56: 273-284.

12. Winkelstein A. Mechanisms of immunosuppression: effects of cyclophosphamide on cellular immunity. Blood 1973;41:273-284.

13. McBride WH, Hoon DB, Jung T, Naungayan J, Nizze A, Morton DL. Cyclophosphamide-induced alterations in human monocyte functions. J Leukoc Biol 1987;42: 659-666.

14. Heneka MT, Carson MJ, El Khoury J, et al. Neuroinflammation in Alzheimer's disease. Lancet Neurol 2015; 14:388-405. 


\section{Neurology \\ Neuroimmunology \& Neuroinflammation}

\section{Reduction of microbleeds by immunosuppression in a patient with $\mathrm{A} \beta$-related vascular inflammation \\ Andreas Traschütz, Theophilos Tzaridis, Arndt-Hendrik Penner, et al. \\ Neurol Neuroimmunol Neuroinflamm 2015;2; \\ DOI 10.1212/NXI.0000000000000165}

This information is current as of October 15, 2015

Updated Information \&

Services

References

Subspecialty Collections

Permissions \& Licensing

Reprints including high resolution figures, can be found at:

http://nn.neurology.org/content/2/6/e165.full.html

This article cites 14 articles, 3 of which you can access for free at: http://nn.neurology.org/content/2/6/e165.full.html\#\#ref-list-1

This article, along with others on similar topics, appears in the following collection(s):

All Immunology

http://nn.neurology.org//cgi/collection/all_immunology

Other cerebrovascular disease/ Stroke

http://nn.neurology.org//cgi/collection/other_cerebrovascular_disease_ _stroke

Information about reproducing this article in parts (figures,tables) or in its entirety can be found online at:

http://nn.neurology.org/misc/about.xhtml\#permissions

Information about ordering reprints can be found online:

http://nn.neurology.org/misc/addir.xhtml\#reprintsus

Neurol Neuroimmunol Neuroinflamm is an official journal of the American Academy of Neurology.

Published since April 2014, it is an open-access, online-only, continuous publication journal. Copyright $(\mathrm{C}$ 2015 American Academy of Neurology. All rights reserved. Online ISSN: 2332-7812.

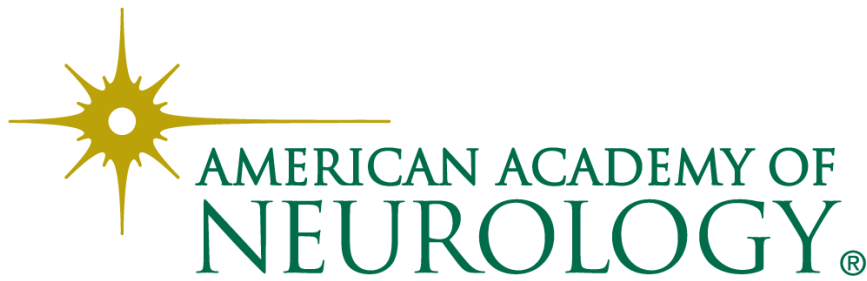

